\title{
Telemedicine for silent hypoxia: Improving the reliability and accuracy of Max30100-based system
}

\author{
Nila Novita Sari, Mina Naidah Gani, Regina Aprilia Maharani Yusuf, Riko Firmando \\ Department of Electrical Engineering, Politeknik Negeri Bandung, Indonesia
}

\begin{tabular}{l} 
Article Info \\
\hline Article history: \\
Received Jan 26, 2021 \\
Revised Apr 29, 2021 \\
Accepted May 1, 2021 \\
\hline
\end{tabular}

Keywords:

COVID-19

Max30100 sensor

Reliability

Silent hypoxia

Telemedicine

\begin{abstract}
This study aims to design, assess, and improve the reliability of the telemedicine-based system for examination and monitoring of the symptoms of silent hypoxia-an extraordinary symptom of COVID-19. We design a telemedicine system for heart rate and oxygen saturation measurement which consists of a photoplethysmograph Max30100 sensor, NodeMCU microcontroller, real-time clock module, firebase realtime database, and Android-based mobile application. The designed system is tested through a comparative test with a commercially available oximeter. A total of 85 experiments from 40 participants in two different positions were conducted. Our analysis shows the accuracy rate of the Max30100 measurement is $97.11 \%$ and $98.84 \%$, for heart rate and oxygen saturation $\left(\mathrm{SpO}_{2}\right)$, respectively. Bland Altman was used to appraising and visualizing the agreement between the two measurement devices. We further apply calibration to improve the accuracy of the collected data through linear regression, which reveals $97.14 \%$ and $99 \%$ accuracy data for heart rate and $\mathrm{SpO}_{2}$, respectively. Finally, a series of end-to-end remote testing is successfully conducted representing the real-life scenario of the telemedicine system. Overall, the designed system attains a reliable option for a telemedicine-based system for examination of the symptoms of silent hypoxia.
\end{abstract}

This is an open access article under the CC BY-SA license.

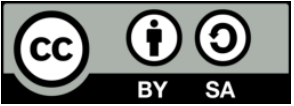

\section{Corresponding Author:}

Nila Novita Sari

Department of Electrical Engineering

Politeknik Negeri Bandung

Bandung, Indonesia

Email: nila.novita@polban.ac.id

\section{INTRODUCTION}

Silent hypoxia is a new symptom of the coronavirus COVID-19 that seems to ignore the basic of human physiology with which the tissue or organs of the infected patients suffer from an extraordinary low oxygen level without apparent signs or symptoms of respiratory distress [1]-[6]. The cause of hypoxia is commonly associated with an insufficient level of oxygen saturation $\left(\mathrm{SpO}_{2}\right)$ within the blood (i.e., hypoxemia) delivering oxygen from lungs to tissue and organs [7]. As such, in normal cases, hypoxia is a prevalent symptom in patients with lung diseases such as pneumonia whose lungs are filled with fluid or cannot expel carbon dioxide efficiently [2], [8], which cause various symptoms such as difficulty in breathing, accelerated heart rate or pulse, changes in skin color, and/or the loses of body balance. However, COVID-19 patients with silent hypoxia have no apparent symptoms of this respiratory distress and often seem clinically well [9], which confuses the doctor [10]. 
The current pandemic of COVID-19 has invited scholars across disciplines to contribute to a better clinical approach to the handling of this virus. Including the extraordinary phenomenon of silent hypoxia found in COVID-19 patients, in which multiple discussions have called for technological interventions that are able to detect early changes in the oxygen saturation value [11]. For example, a senior emergency doctor in a hospital in New York [11] suggests that earlier handling of detection of silent hypoxia is crucial in the treatment of the COVID-19 patients. Most patients admitted to the hospital failed to detect their oxygenation and heart rate much earlier that at one point they suddenly dropped into an acute critical condition. As such, many doctors have emphasized the beneficial use of the "pulse oximeter" as a reliable device for an early warning system in dealing with the problem of pneumonia in COVID-19. However, while the pulse oximeter device has been increasingly useful in clinical practice, this device has a limitation as it requires physical contact between health workers and patients. In this regard, telemedicine is seen as a critical and urgent solution that can transform beyond conventional physical contact clinical practice during this global emergency of COVID-19 [12]. In particular, a telemedicine system can assist families and health professionals to conveniently monitor the patients' oxygen saturation in regular time intervals [13].

A number of studies have attempted to develop telemedicine systems intended for detecting silent hypoxia. Iswanto and Megantoro [14], for instance, developed a system based on the Arduino microcontroller and MAX30100 sensor. Using the fuzzy method for the classification process, the prototype sends the data via Bluetooth to be displayed in the Android application. While the approach seems promising, the system, however, was limited in its accuracy, that the accuracy rate obtained in oxygen saturation measurement is at $97.04 \%$ while the accuracy rate for heart rate measurement is at $97.14 \%$. Nevertheless, the previous study approach to utilize smartphones in designing telemedicine for silent hypoxia detection is worth noting because, as Teo [15] suggests, it has been proven as an efficient yet highly reliable assistive technology in the measurements of vital parameters [16].

Drawn from the results of the previous studies, our present work attempts to develop a more accurate telemedicine system that obtains the data from the pulse oximeter sensor in use and transmits it to a smartphone display to enable distant monitoring. We use MAX30100 as the sensor with an optical measurement technique to detect blood volume change in the microvascular bed of tissue (i.e., photoplethysmograph) [17], [18]. We use Google firebase as a feasible backend in telemedicine system [19]-[22] that stores the captured data real-time and subsequently is displayed on a smartphone with an Android platform so that both intended user and health care providers can monitor the oxygen saturation and heart rate condition of the user remotely.

\section{RESEARCH METHOD}

\subsection{System overview}

The system, as shown in Figure 1, comprises three subsystems: the hardware (module device), database (firebase), and software (Android application). The hardware/module device consists of three parts: i) The MAX30100 sensor that collects the data input on the heart rate and oxygen saturation; ii) The NodeMCU ESP8266 Arduino microcontroller that processes the collected data; and iii) real-time clock (RTC) DS3231 module that monitors and tracks the real-time of such a data. Max30100 is integrated pulse oximetry and heart rate monitor sensor that combines optimized optics, a photodetector, two LEDs, and low-noise analog signal processing to detect heart-rate signals and pulse oximetry [23]. Before sending the data to the firebase, we configure the microcontroller to calibrate the collected data (from MAX30100 output) using the linear regression and Bland Altman analysis. Bland Altman analysis is commonly used to compare two measurement methods, where this system will compare the MAC30100 sensor with General care $^{\circledR}$ devices [24], [25]. Through its Wi-Fi module, the NodeMCU microcontroller sends the calibrated data to the firebase storing the data in a real-time fashion which subsequently sends it to the Android application.

Figure 2 shows the flowchart of the system starting from the input (Max30100 sensor) to the output (the android application). When the system is on, the microcontroller continuously checks whether the sensor is collecting data (heart rate and $\mathrm{SPO}_{2}$ ), or not. Once the sensor is collecting data, the microcontroller calibrates the collected data and subsequently displays it in a 16x2 liquid crystal display (LCD) while also send it online to the database. In addition to such a calibrated data, the LCD also displays the timestamp based on the real-time clock module. Once the database received the real-time data, the Android application pops up a notification as a reminder that the sensor has sent the latest data and is ready to be displayed on the application. 


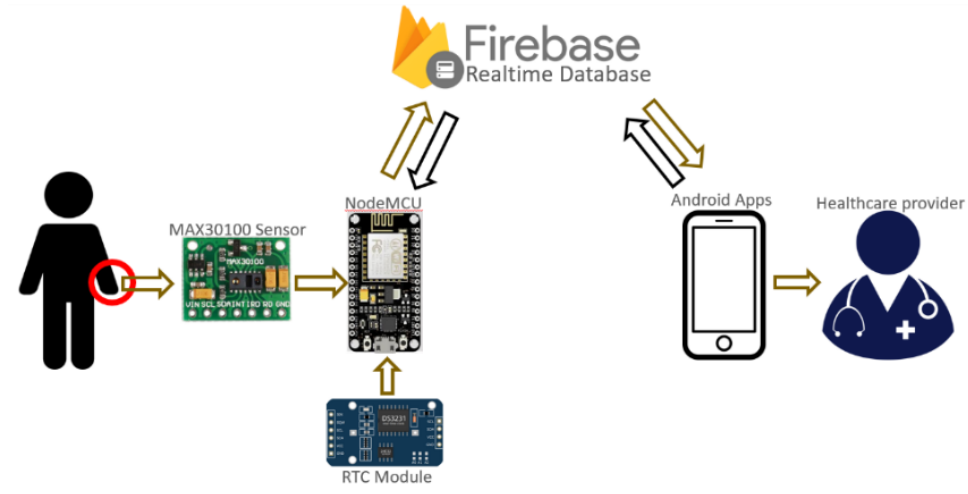

Figure 1. Block diagram of the system

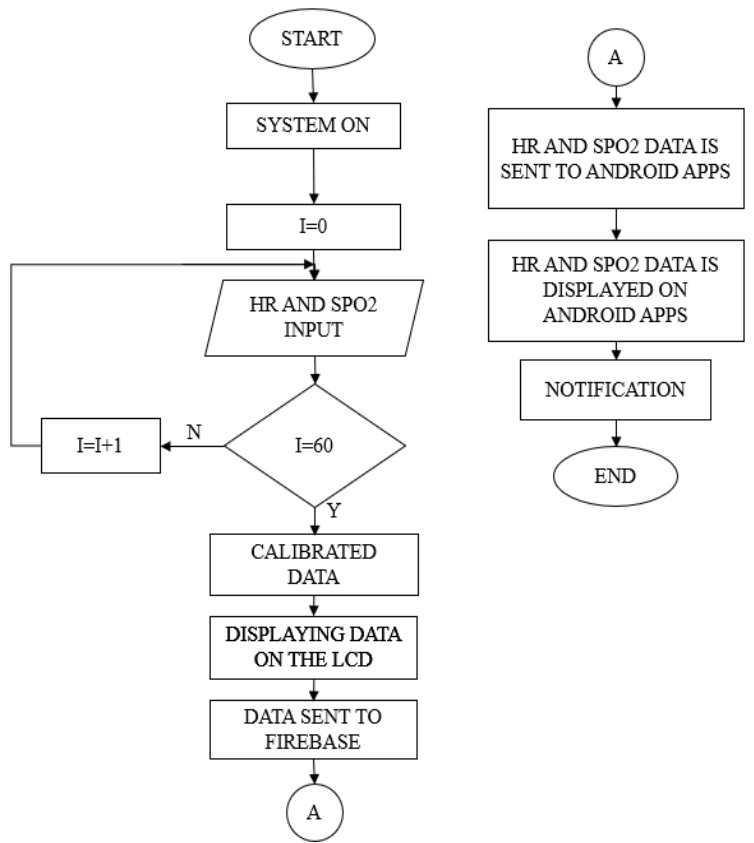

Figure 2. System flowchart

\subsection{System devising}

The wiring components of the MAX30100 module on the side of the measurement device is shown in Figure 3. Based on the wiring diagram, we implement the system comprising LCD, RTC module, NodeMCU, and Max30100. Figure 4 presents the result of our module.

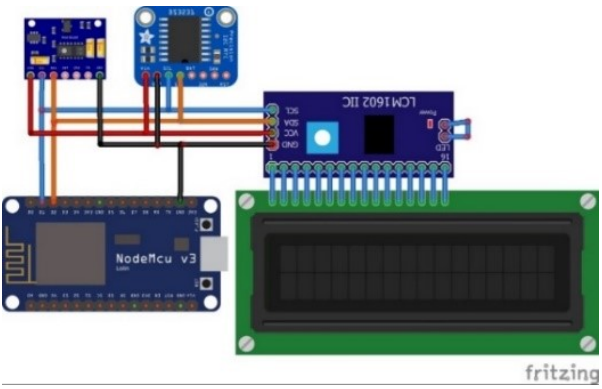

Figure 3. Wiring diagram

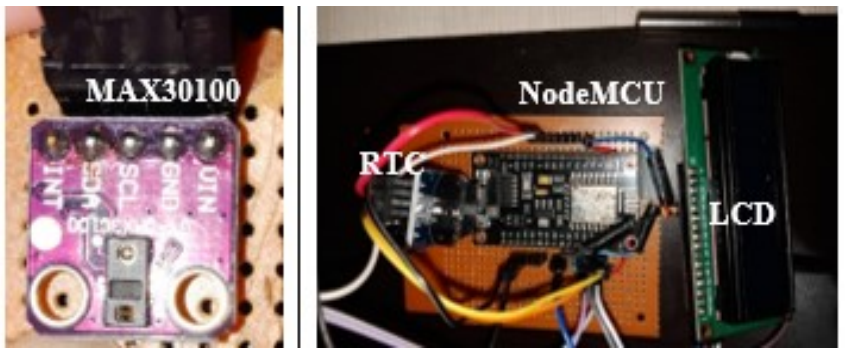

Figure 4. Max30100 hardware module 


\subsection{Software design}

\subsubsection{Arduino microcontroller}

We configure the microcontroller using Arduino integrated development environment (IDE) to perform a series of tasks ranging from system initialization to device-database connection. The system initialization initiates the variables used in the module device representing the pulse oximeter, the RTC, and the device display. We configure and apply an authentication process for wireless fidelity (Wi-Fi)-Google firebase connection.

\subsubsection{Google firebase}

The firebase Realtime database service, as used in our system, is one of the services provided by firebase Google platforms which offer a wide range of products and services for application development. This service provides an application programming interface (API) that allows application data to be synchronized across users and stored in the firebase cloud. For our system, we created an account in the Firebase console and configured the firebase realtime database as shown in Figure 5.

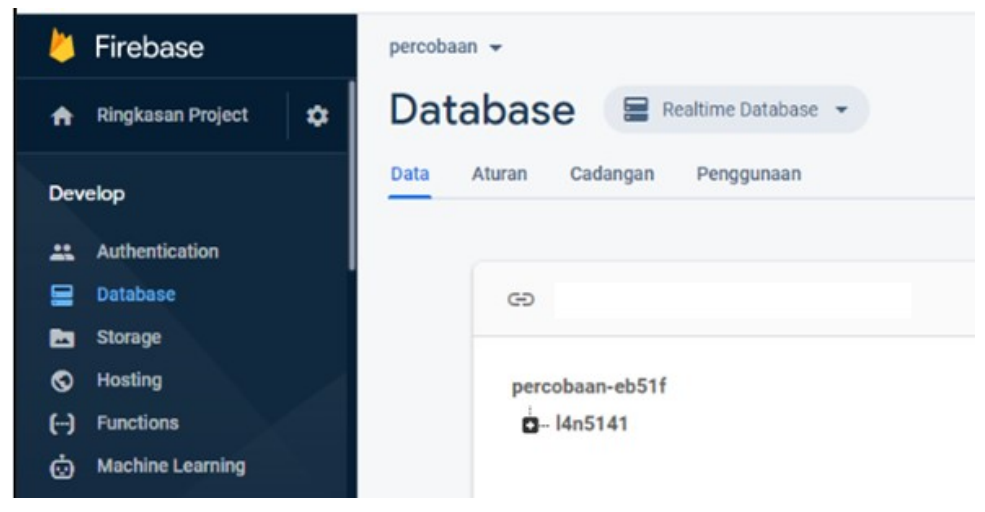

Figure 5. Google firebase console

\subsection{Data collection}

We conducted a series of experiments for data collection to examine the reliability of our system. A total of 85 experiments were conducted on 40 participants (some participated in multiple experiments), 26 of which are female and 14 of which are male with an average age was 43 and 41 years, respectively. The experiments were conducted in the participants' location. The experiments collected data on participants' HR and $\mathrm{SpO}_{2}$ in the sitting and supine position, all of which were conducted for about 5 months from [July-November 2020] in our participants' location.

\section{RESULTS AND DISCUSSION}

Table 1 (see appendix) presents the overall results of our experiments. We analyze the level of accuracy of our experiments by comparing our generated data from MAX30100 to the commercial HR and $\mathrm{SpO}_{2}$ measurement device named General care ${ }^{\circledR}$. Table 2 presents the comparison of the collected data between Max30100 against the commercial device. Overall, the mean and standard deviation between the data from the commercial device and Max30100 are quite alike.

Table 2. Comparison of the heart rate and $\mathrm{SpO}_{2}$ measured by the General care ${ }^{\circledR}$ device and Max30100 sensor

\begin{tabular}{|c|c|c|c|c|}
\hline & $\begin{array}{l}\text { HR calculated by } \\
\text { General care }{ }^{\circledR}\end{array}$ & $\begin{array}{c}\text { HR calculated by } \\
\text { Max } 30100\end{array}$ & $\begin{array}{c}\mathrm{SpO}_{2} \text { calculated by } \\
\text { General care }^{\circledR}\end{array}$ & $\begin{array}{c}\mathrm{SpO}_{2} \text { calculated by } \\
\text { Max30100 }\end{array}$ \\
\hline Mean & 79.16470588 & 78.22270588 & 97.694118 & 97.105882 \\
\hline Median & 80 & 78.5 & 98 & 98 \\
\hline $\begin{array}{l}\text { Standard } \\
\text { deviation }\end{array}$ & 10.42187153 & 10.9793188 & 1.3889318 & 1.4311461 \\
\hline $\begin{array}{l}\text { Standard error } \\
\text { of the mean }\end{array}$ & 1.13041 & 1.190874327 & 0.1506508 & 0.1552296 \\
\hline Regression equation & & $y=0.91772 x+7.37803$ & & $y=0.52168 x+47.0362$ \\
\hline Slope & & 0.917721705 & & 0.5216767 \\
\hline Interception & & 7.378030835 & & 47.036242 \\
\hline
\end{tabular}


In (1) and (2) are used to examine the accuracy and error rate of the sensor output data (Table 1), resulting in a fairly low error value of $2.89 \%$ and an accuracy of $97.11 \%$ for the heart rate data. The data calibration of $\mathrm{SpO}_{2}$ also results in desirable outcomes, where the error value is $1.15 \%$ with a high level of accuracy of $98.84 \%$.

$$
\begin{aligned}
& \% \text { Error }=\frac{\text { Average }\left(\mid \text { General } \text { Care }{ }^{\circledR} \text { reading-MAX30100 reading } \mid\right)}{\text { Average }\left(\text { General Care }{ }^{\circledR} \text { reading }\right)} \times 100 \% \\
& \% \text { Accuracy }=100 \%-\% \text { Error }
\end{aligned}
$$

Figure 6 shows the plot of Bland Altman's analysis results, in which the solid line represents the mean bias values of 0.94 and 0.59 for $\mathrm{HR}$ and $\mathrm{SpO}_{2}$, respectively. The dotted line represents the limit of agreement (LOA) in the upper value, while the dashed line represents the lower value of LOA. Based on the figure, we found 4 outlier data out of the total 84 data in HR. On the other hand, we found 2 outlier data (out of 84) in $\mathrm{SpO}_{2}$.
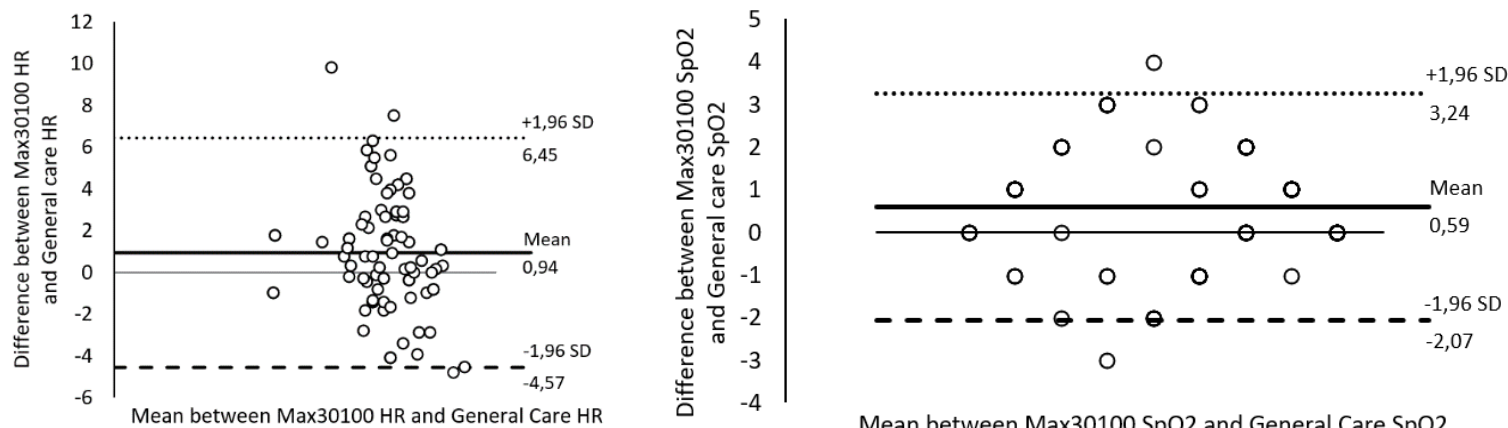

Mean between Max30100 SpO2 and General Care SpO2

Figure 6. Plots of the Bland Altman for differences in Heart Rate and $\mathrm{SpO}_{2}$ measurements between the general care and Max30100 sensor

We applied a calibration to further increase the accuracy of the data before sending it to the firebase database. The data captured by MAX30100 is calibrated through the linear regression analysis to obtain more accurate results on this system. The formula of the linear regression for each measuring parameter is in Table 2. The result of this calibration process increases the accuracy to $97.14 \%$ and $99 \%$ for heart rate and oxygen saturation, respectively. Based on these results, it can be implied that the Max30100 sensor is considerably accurate in measuring heart rate activity and oxygen levels in the blood. On measurement side, the LCD displays the results of heart rate and $\mathrm{SpO}_{2}$ data as seen in Figure 7.

Finally, Figure 8 shows the outcomes in the firebase database (submitted from NodeMCU microcontroller) and the display in Android apps. We experimented with remote testing in which one field assistant was conducting the direct measurement using our system device on a research participant and another one through a zoom meeting was receiving the data over the internet network in a smartphone, thus enacting a successful telemedicine real-life scenario.

Overall, our present work has extended the previous research, particularly in [14], since it offers a more reliable system due to three enhancements. First, our system has enhanced the accuracy and reliability by applying a calibration to the proposed solution. Second, our system has been tested with far richer actual experimental data which produces more reliable analysis. Third, our designed system is able to communicate with the database and smartphone through an internet network, rather than Bluetooth, which represents a real-world scenario of telemedicine.

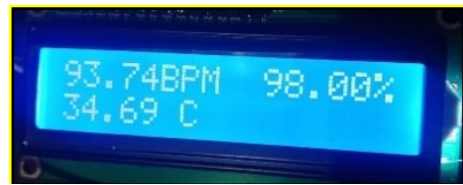

Figure 7. Display results on the LCD side of the measurement 


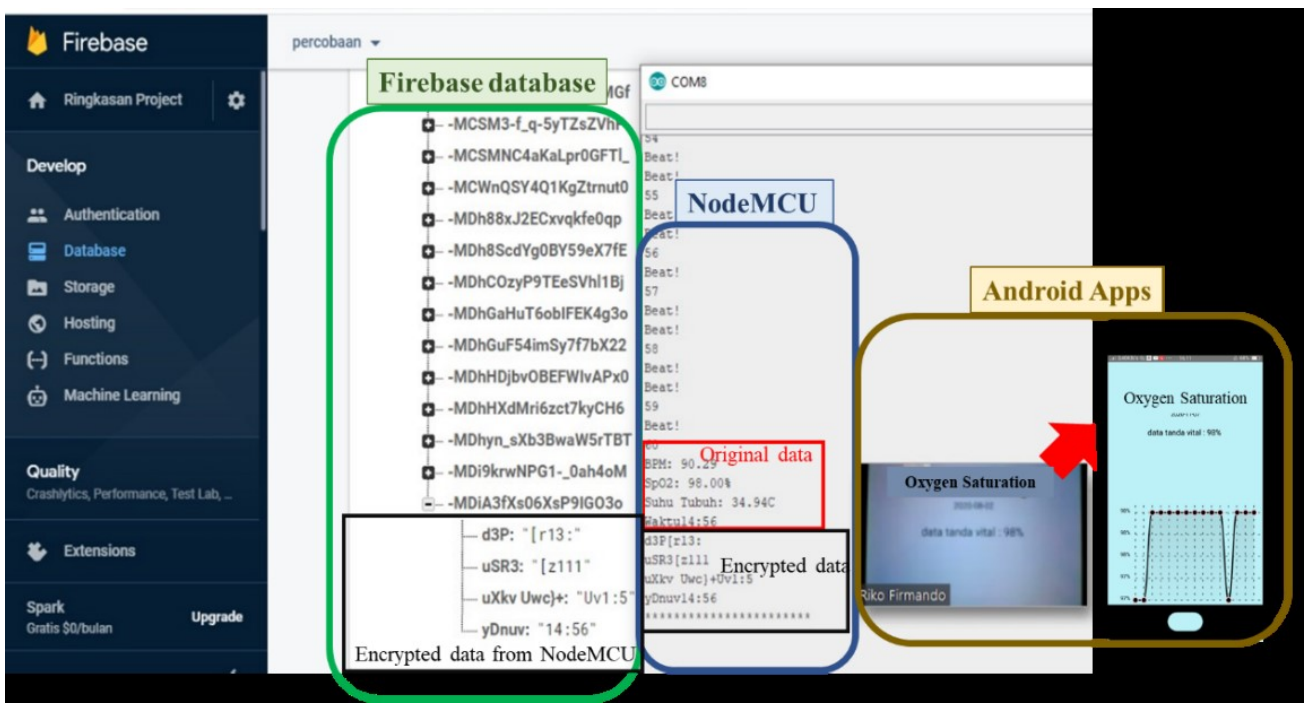

Figure 8. Results of a telemedicine-based experiment: firebase database (left), and an Android application (remotely through zoom meeting) that displays the measurement results (right)

\section{CONCLUSION}

This study has succeeded in designing, assessing, and improved a telemedicine-based system for examination and monitoring of the symptoms of silent hypoxia. The designed system, which consists of a photoplethysmograph Max30100 sensor, NodeMCU microcontroller, real-time clock module, firebase realtime database, and Android-based mobile application, has been successfully remote-tested to measure heart rate and oxygen saturation, calibrated, sent, and displayed in a smartphone. Through a comparative test with a commercially available oximeter, this study shows the reliability of using the Max30100 sensor as an alternative solution for the measurement of heart rate and oxygen saturation.

Nevertheless, this study has some limitations that in turn offers an opportunity for future research. First, the experiments were conducted on participants with a relatively similar range of age, thus we recommend the future research consider a more varied population of subjects and possibly larger samples. Second, future research could extend the analysis by performing and providing a classification of the captured data so that the information presented at end-user is more descriptive and beneficial.

\section{APPENDIX}

Tabel 1. Measurement of heart rate ans $\mathrm{SpO}_{2}$ using general care and $\mathrm{Max} 30100$

\begin{tabular}{cccccccc}
\hline \multirow{2}{*}{ No } & \multirow{2}{*}{ Gender } & \multicolumn{2}{c}{ HR General Care ${ }^{\circledR}$-Max30100 } & \multicolumn{3}{c}{ SpO $_{2}$ General Care $^{\circledR}$-Max30100 } \\
& & General Care $\mathbb{R}$ & MAX 30100 & \%Error & General Care & MAX 30100 & \%Error \\
\hline 1 & $\mathrm{~F}$ & 46 & 47.1 & 2.39 & 97 & 98 & 1.03 \\
2 & $\mathrm{~F}$ & 79 & 76.11 & 3.66 & 99 & 99 & 0.00 \\
3 & $\mathrm{M}$ & 76 & 70.23 & 7.59 & 99 & 96 & 3.03 \\
4 & $\mathrm{~F}$ & 83 & 80.32 & 3.23 & 99 & 99 & 0.00 \\
5 & $\mathrm{~F}$ & 85 & 85.45 & 0.53 & 99 & 96 & 3.03 \\
6 & $\mathrm{~F}$ & 68 & 68.25 & 0.37 & 98 & 98 & 0.00 \\
7 & $\mathrm{~F}$ & 77 & 72 & 6.49 & 99 & 99 & 0.00 \\
8 & $\mathrm{M}$ & 78 & 78.35 & 0.45 & 96 & 95 & 1.04 \\
9 & $\mathrm{~F}$ & 84 & 83.96 & 0.05 & 96 & 97 & 1.04 \\
10 & $\mathrm{~F}$ & 84 & 79.86 & 4.93 & 99 & 99 & 0.00 \\
11 & $\mathrm{~F}$ & 83 & 80.32 & 3.23 & 99 & 99 & 0.00 \\
12 & $\mathrm{M}$ & 85 & 86.3 & 1.53 & 99 & 99 & 0.00 \\
13 & $\mathrm{~F}$ & 77 & 72 & 6.49 & 99 & 99 & 0.00 \\
14 & $\mathrm{M}$ & 46 & 47.1 & 2.39 & 98 & 97 & 1.02 \\
15 & $\mathrm{M}$ & 48 & 46.3 & 3.54 & 97 & 98 & 1.03 \\
16 & $\mathrm{~F}$ & 68 & 58.25 & 14.34 & 98 & 98 & 0.00 \\
17 & $\mathrm{~F}$ & 77 & 78.95 & 2.53 & 98 & 95 & 3.06 \\
18 & $\mathrm{~F}$ & 72 & 73.96 & 2.72 & 98 & 95 & 3.06 \\
19 & $\mathrm{M}$ & 85 & 85.45 & 0.53 & 99 & 97 & 2.02 \\
20 & $\mathrm{M}$ & 85 & 82.42 & 3.04 & 99 & 99 & 0.00 \\
\hline
\end{tabular}


Tabel 1. Measurement of heart rate ans $\mathrm{SpO}_{2}$ using general care and Max30100 (continue)

\begin{tabular}{|c|c|c|c|c|c|c|c|}
\hline \multirow{2}{*}{ No } & \multirow{2}{*}{ Gender } & \multicolumn{3}{|c|}{ HR General Care ${ }^{\circledR}$-Max30100 } & \multicolumn{3}{|c|}{$\mathrm{SpO}_{2}$ General Care ${ }^{\mathbb{R}}-\mathrm{Max} 30100$} \\
\hline & & General Care ${ }^{\circledR}$ & MAX 30100 & $\%$ Error & General Care $\mathbb{R}$ & MAX 30100 & $\%$ Error \\
\hline 21 & $\mathrm{~F}$ & 76 & 76.23 & 0.30 & 99 & 98 & 1.01 \\
\hline 22 & $\mathrm{~F}$ & 73 & 73.55 & 0.75 & 99 & 99 & 0.00 \\
\hline 23 & M & 86 & 90.01 & 4.66 & 96 & 98 & 2.08 \\
\hline 24 & $\mathrm{~F}$ & 78 & 78.35 & 0.45 & 96 & 95 & 1.04 \\
\hline 25 & $\mathrm{~F}$ & 69 & 67.48 & 2.20 & 99 & 97 & 2.02 \\
\hline 26 & $\mathrm{~F}$ & 69 & 68.79 & 0.30 & 99 & 98 & 1.01 \\
\hline 27 & $\mathrm{~F}$ & 87 & 82.63 & 5.02 & 99 & 99 & 0.00 \\
\hline 28 & $\mathrm{~F}$ & 87 & 83.28 & 4.28 & 99 & 98 & 1.01 \\
\hline 29 & $\mathrm{~F}$ & 73 & 72.36 & 0.88 & 95 & 96 & 1.05 \\
\hline 30 & $\mathrm{~F}$ & 72 & 72.36 & 0.50 & 97 & 95 & 2.06 \\
\hline 31 & $\mathrm{~F}$ & 74 & 71.47 & 3.42 & 96 & 95 & 1.04 \\
\hline 32 & $\mathrm{~F}$ & 96 & 100.85 & 5.05 & 96 & 96 & 0.00 \\
\hline 33 & M & 71 & 73.89 & 4.07 & 96 & 95 & 1.04 \\
\hline 34 & M & 67 & 66.34 & 0.99 & 95 & 95 & 0.00 \\
\hline 35 & M & 95 & 94.76 & 0.25 & 97 & 95 & 2.06 \\
\hline 36 & M & 76 & 76.91 & 1.20 & 97 & 95 & 2.06 \\
\hline 37 & $\mathrm{~F}$ & 95 & 94.03 & 1.02 & 97 & 98 & 1.03 \\
\hline 38 & M & 78 & 82.22 & 5.41 & 95 & 98 & 3.16 \\
\hline 39 & $\mathrm{~F}$ & 77 & 76.82 & 0.23 & 96 & 98 & 2.08 \\
\hline 40 & M & 95 & 94.03 & 1.02 & 98 & 98 & 0.00 \\
\hline 41 & $\mathrm{~F}$ & 48 & 46.3 & 3.54 & 97 & 98 & 1.03 \\
\hline 42 & $\mathrm{~F}$ & 80 & 77.47 & 3.16 & 99 & 98 & 1.01 \\
\hline 43 & M & 75 & 74.36 & 0.85 & 96 & 95 & 1.04 \\
\hline 44 & M & 75 & 72.95 & 2.73 & 96 & 95 & 1.04 \\
\hline 45 & $\mathrm{~F}$ & 83 & 77.53 & 6.59 & 95 & 95 & 0.00 \\
\hline 46 & $\mathrm{~F}$ & 85 & 82.42 & 3.04 & 99 & 99 & 0.00 \\
\hline 47 & $\mathrm{~F}$ & 77 & 78.5 & 1.95 & 98 & 96 & 2.04 \\
\hline 48 & $\mathrm{~F}$ & 83 & 80.2 & 3.37 & 95 & 96 & 1.05 \\
\hline 49 & M & 69 & 67.48 & 2.20 & 99 & 97 & 2.02 \\
\hline 50 & $\mathrm{~F}$ & 74 & 75.48 & 2.00 & 97 & 98 & 1.03 \\
\hline 51 & $\mathrm{~F}$ & 82 & 80.28 & 2.10 & 99 & 98 & 1.01 \\
\hline 52 & $\mathrm{~F}$ & 85 & 77.57 & 8.74 & 95 & 95 & 0.00 \\
\hline 53 & M & 83 & 80.2 & 3.37 & 96 & 95 & 1.04 \\
\hline 54 & $\mathrm{~F}$ & 80 & 78.44 & 1.95 & 99 & 95 & 4.04 \\
\hline 55 & M & 87 & 82.63 & 5.02 & 99 & 99 & 0.00 \\
\hline 56 & M & 84 & 79.88 & 4.90 & 99 & 98 & 1.01 \\
\hline 57 & $\mathrm{~F}$ & 82 & 85.47 & 4.23 & 98 & 98 & 0.00 \\
\hline 58 & $\mathrm{~F}$ & 74 & 75.48 & 2.00 & 97 & 98 & 1.03 \\
\hline 59 & $\mathrm{~F}$ & 74 & 75.41 & 1.91 & 97 & 98 & 1.03 \\
\hline 60 & $\mathrm{~F}$ & 78 & 82.22 & 5.41 & 96 & 98 & 2.08 \\
\hline 61 & $\mathrm{~F}$ & 86 & 84.61 & 1.62 & 97 & 95 & 2.06 \\
\hline 62 & $\mathrm{~F}$ & 89 & 88.53 & 0.53 & 96 & 97 & 1.04 \\
\hline 63 & M & 84 & 82.41 & 1.89 & 98 & 95 & 3.06 \\
\hline 64 & $\mathrm{~F}$ & 90 & 92.97 & 3.30 & 95 & 97 & 2.11 \\
\hline 65 & $\mathrm{~F}$ & 61 & 59.66 & 2.20 & 96 & 95 & 1.04 \\
\hline 66 & M & 82 & 78.18 & 4.66 & 98 & 95 & 3.06 \\
\hline 67 & M & 87 & 90.01 & 3.46 & 96 & 95 & 1.04 \\
\hline 68 & M & 68 & 66.95 & 1.54 & 99 & 97 & 2.02 \\
\hline 69 & M & 78 & 71.76 & 8.00 & 99 & 97 & 2.02 \\
\hline 70 & M & 78 & 72.58 & 6.95 & 98 & 97 & 1.02 \\
\hline 71 & M & 81 & 77.3 & 4.57 & 99 & 97 & 2.02 \\
\hline 72 & M & 80 & 78.57 & 1.79 & 98 & 97 & 1.02 \\
\hline 73 & M & 79 & 80.8 & 2.28 & 99 & 97 & 2.02 \\
\hline 74 & M & 99 & 103.62 & 4.67 & 99 & 98 & 1.01 \\
\hline 75 & M & 93 & 92.97 & 0.03 & 98 & 98 & 0.00 \\
\hline 76 & $\mathrm{~F}$ & 90 & 91.06 & 1.18 & 99 & 98 & 1.01 \\
\hline 77 & $\mathrm{~F}$ & 87 & 87.14 & 0.16 & 99 & 98 & 1.01 \\
\hline 78 & $\mathrm{~F}$ & 78 & 73.66 & 5.56 & 99 & 98 & 1.01 \\
\hline 79 & $\mathrm{~F}$ & 85 & 82.19 & 3.31 & 99 & 98 & 1.01 \\
\hline 80 & $\mathrm{~F}$ & 81 & 80.13 & 1.07 & 99 & 98 & 1.01 \\
\hline 81 & $\mathrm{~F}$ & 92 & 92.94 & 1.02 & 98 & 99 & 1.02 \\
\hline 82 & $\mathrm{~F}$ & 86 & 85.84 & 0.19 & 99 & 98 & 1.01 \\
\hline 83 & $\mathrm{~F}$ & 92 & 92.9 & 0.98 & 99 & 97 & 2.02 \\
\hline 84 & $\mathrm{~F}$ & 92 & 92.1 & 0.11 & 98 & 98 & 0.00 \\
\hline \multirow[t]{3}{*}{85} & $\mathrm{~F}$ & 73 & 70.74 & 3.10 & 98 & 98 & 0.00 \\
\hline & Sum & 6729 & 6648.93 & 245.27 & 8304 & 8254 & 98.3 \\
\hline & Average & 79.16 & 78.22 & 2.89 & 97.69 & 97.10 & 1.15 \\
\hline
\end{tabular}




\section{REFERENCES}

[1] A. Lari, M. Alherz, A. Nouri, L. Botras, and S. Taqi, "Caution against precaution: A case report on silent hypoxia in COVID-19," Annals of Medicine and Surgery, vol. 60, no. November, pp. 301-303, 2020, doi: 10.1016/j.amsu.2020.11.007.

[2] J. Couzin-Frankel, "The mystery of the pandemic's 'happy hypoxia," Science, vol. 368, no. 6490, 2020.

[3] M. J. Tobin, F. Laghi, and A. Jubran, "Why COVID-19 silent hypoxemia is baffling to physicians," American Journal of Respiratory and Critical Care Medicine, vol. 202, no. 3, pp. 356-360, 2020, doi: 10.1164/rccm.202006$2157 \mathrm{CP}$.

[4] R. G. Wilkerson, J. D. Adler, N. G. Shah, and R. Brown, "Silent hypoxia: A harbinger of clinical deterioration in patients with COVID-19," American Journal of Emergency Medicine, vol. 38, no. 10, October, pp. 2243.e5-2243.e6, 2020.

[5] A. Chandra, U. Chakraborty, J. Pal, and P. Karmakar, "Silent hypoxia: A frequently overlooked clinical entity in patients with COVID-19," BMJ Case Reports, vol. 13, no. 9, 2020, doi: 10.1136/bcr-2020-237207.

[6] N. J. U. Fuglebjerg, T. O. Jensen, N. Hoyer, C. K. Ryrsø, B. L. Madsen, and Z. B. Harboe, "Silent hypoxia in patients with SARS CoV-2 infection before hospital discharge," International Journal of Infectious Diseases, vol. 99, pp. 100-101, 2020, doi: 10.1016/j.ijid.2020.07.014.

[7] B. S. Bhutta, F. Alghoula, I. Berim, and S. Z. Hospital, "Anoxia," Statpearls, 2020

[8] N. D. Caputo, R. J. Strayer, and R. Levitan, "Early self-proning in awake, non-intubated patients in the emergency department: A single ED's experience during the COVID-19 pandemic," Academic Emergency Medicine, vol. 27, no. 5, pp. 375-378, 2020, doi: 10.1111/acem.13994.

[9] C. Machado, P. A. Defina, Y. Machado, and M. Chinchilla, "From happy or silent hypoxemia to acute respiratory syndrome in COVID-19 disease," Journal of Clinical Neurology and Neuroscience, no. November, 2020, doi: 10.1001/jamainternmed.2020.0994.29.

[10] A. Widysanto et al., "Happy hypoxia in critical COVID-19 patient: A case report in Tangerang, Indonesia," Physiological Reports, vol. 8, no. 20, pp. 1-5, 2020, doi: 10.14814/phy2.14619.

[11] R. Levitan, "The infection that's silently killing coronavirus patients," The New York Times, 2020. https://www.nytimes.com/2020/04/20/opinion/sunday/coronavirus-testing-pneumonia.html (accessed Dec. 30, 2020).

[12] A. C. Smith et al., "Telehealth for global emergencies: Implications for coronavirus disease 2019 (COVID-19)," Journal of Telemedicine and Telecare, vol. 26, no. 5, pp. 309-313, 2020, doi: 10.1177/1357633X20916567.

[13] S. Dhont, E. Derom, E. Van Braeckel, P. Depuydt, and B. N. Lambrecht, "The pathophysiology of 'happy' hypoxemia in COVID-19," Respiratory Research, vol. 21, no. 1, pp. 1-10, 2020, doi: 10.1186/s12931-020-01462-5.

[14] Iswanto and P. Megantoro, "Detection of hypoxic symptoms system based on oxygen saturation and heart rate using Arduino based fuzzy method," in 2nd International Conference on Industrial Electrical and Electronics (ICIEE), 2020, pp. 107-111.

[15] J. Teo, "Early detection of silent hypoxia in COVID-19 pneumonia using smartphone pulse oximetry," Journal of Medical Systems, vol. 44, no. 8, pp. 6-7, 2020, doi: 10.1007/s10916-020-01587-6.

[16] İ. Tayfur and M. A. Afacan, "Reliability of smartphone measurements of vital parameters: A prospective study using a reference method," American Journal of Emergency Medicine, vol. 37, pp. 1527-1530, 2019, doi: 10.1016/j.ajem.2019.03.021.

[17] Y. P. Huang, N. N. Sari, and T. T. Lee, "Early detection of driver drowsiness by WPT and FLFNN models," 2016 IEEE International Conference on Systems, Man, and Cybernetics, SMC 2016 - Conference Proceedings, pp. 463-468, 2017, doi: 10.1109/SMC.2016.7844283.

[18] N. F. A. Jamal, K. A. Sidek, and A. Z. Jusoh, "Portable health monitoring kit using photolethysmogram signal," Indonesian Journal of Electrical Engineering and Computer Science, vol. 15, no. 2, pp. 638-649, 2019, doi: 10.11591/ijeecs.v15.i2.pp638-649.

[19] A. Mukhopadhyay, B. Xavier, S. Sreekumar, and M. Suraj, "Real-time ECG monitoring over multi-tiered telemedicine environment using firebase," 2018 International Conference on Advances in Computing, Communications and Informatics, ICACCI 2018, 2018, pp. 631-637, doi: 10.1109/ICACCI.2018.8554736.

[20] A. Kumar Sharma and L. Mohan Saini, "IoT based diagnosing myocardial infarction through firebase web application," Proceedings of the 3rd International Conference on Electronics and Communication and Aerospace Technology, ICECA 2019, 2019, pp. 190-195, doi: 10.1109/ICECA.2019.8822150.

[21] S. A. Riffat, F. Harun, and T. Hassan, "An interactive tele-medicine system via android application," Proceedings 2020 Advanced Computing and Communication Technologies for High Performance Applications, ACCTHPA 2020, 2020, pp. 148-152, doi: 10.1109/ACCTHPA49271.2020.9213200.

[22] K. M. Tsiouris et al., "Designing interoperable telehealth platforms: bridging IoT devices with cloud infrastructures," Enterprise Information Systems, vol. 14, no. 8, pp. 1194-1218, 2020, doi: 10.1080/17517575.2020.1759146

[23] R. K. Parate and S. J. Sharma, "Design of a portable health monitoring system based on node MCU," International Journal of Engineering and Advanced Technology, vol. 9, no. 2, pp. 957-960, 2019, doi: 10.35940/ijeat.a2081.129219.

[24] N. Ö. Doğan, "Bland-Altman analysis: A paradigm to understand correlation and agreement," Turkish Journal of Emergency Medicine, vol. 18, no. 4, pp. 139-141, 2018, doi: 10.1016/j.tjem.2018.09.001.

[25] D. Giavarina, "Understanding Bland Altman analysis," Biochemia Medica, vol. 25, no. 2, pp. 141-151, 2015, doi: 10.11613/BM.2015.015. 